\title{
Evaluating HIV/Aids prevalence and sustainable development in sub-Saharan Africa: the role of health expenditure
}

\author{
Jamiu Adetola Odugbesan ${ }^{1}$, Husam Rjoub ${ }^{2}$
}

\begin{abstract}
1. Department of Business Administration, Faculty of Economics and Administrative Sciences, Cyprus International University, North Cyprus.

2. Department of Accounting and Finance, Faculty of Economics and Administrative Sciences, Cyprus International University, North Cyprus.
\end{abstract}

\begin{abstract}
:
Background: The sub-Saharan Africa (SSA) present the highest prevalence of HIV/AIDS worldwide; resulting to a significant development challenges at country, region and global level. The previous studies explain at least in part, the impact of the epidemic, however the impact of HIV/AIDS in long-term economic behavior were not yet clear. There is clearly few or absence of studies on the impact of the impact of the epidemic on sustainable development.

Objective: This study focused on macroeconomic analysis of the HIV/AIDS impact on sustainable development in SSA.

Method: The study utilized a panel dataset covering 23 countries from 1993 until 2016, and employed Panel ARDL/PMG.

Results: Our findings reveals a stable long-run relationship between sustainable development and HIV/AIDS prevalence. The error correction coefficient was statistically significant and conclude that HIV/AIDS prevalence has long-run impact on sustainable development.

Conclusion: The main implication of our study is that, achieving a sustainable development in the presence of high prevalence of HIV/AIDS in SSA is very challenging and as such, the responsiveness of HIV/AIDS to sustainable development should be maintained at minimum which would require more efforts on HIV/AIDS control programs and increase health expenditure.
\end{abstract}

Keywords: HIV/AIDS; macroeconomics; sustainable development; health expenditure; SSA.

DOI: https://doi.org/10.4314/ahs.v20i2.4

Cite as: Odugbesan JA, Rjoub H. Evaluating HIV/Aids prevalence and sustainable development in sub-Sabaran Africa: the role of health expenditure. Afri Health Sci. 2020; 20(2): 568-578. https://doi.org/10.4314/abs.v20i2.4

\section{Introduction}

Since the turn of the 20th century, the world has been experiencing dramatic changes in its development and the speed of changes exhibit no sign of abatement. The global atention for development tilted to a path that enhances more consumption of resources which will not only constitute a threat to world's natural resources but also alter the environmental structures and perform a critical role in affecting the climate. The GDP, HDI, and ecological footprint have long been used to track country's development ${ }^{1}$, but many have shown that these indices can fail to determine whether a development is sustainable or not $^{2,3}$. By contrast, the Adjusted

\section{Corresponding author: \\ Jamiu Adetola Odugbesan, Department of Business Administration, Faculty of Economics and Administrative Sciences, Cyprus International University, North Cyprus. email: odugbesanadetola@yahoo.com, 20156217@student.ciu.edu.tr}

Net Savings (ANS) was designed to estimate sustainable development ${ }^{4,5}$.

In as many studies abounds on the definition of sustainable development (SD), a definition by World Bank simply put sustainable development as "a development path which can be maintained, in as much the total welfare of the people does not decline along the path". An important point of reference for sustainable development was the report published in 1987 by Brundtland Commission entitled Our Common Future, which defined SD as "development that meets the needs of the present without compromising the ability of future generations to meet their own need"7.

Meanwhile, it was observed that, countries were asked to migrate into a new concept of measuring or tracking development progress without no concrete and agreeable new metrics for evaluating progress, these left countries with no alternative but to continue using GDP to track development ${ }^{7}$. It is imperative to note that many scholars are working on these ${ }^{5,8-10}$. Among the worthy literature to note is the recent work by Lange et al., ${ }^{4}$ on estimating the wealth of nations. Among the indi- 
cators being considered for measuring sustainable development is "Adjusted Net Savings" (ANS), which was opined to be more efficient than other indicators4.

The sustainable development agenda for 2030 has health at the center ${ }^{11}$. The goal is "to ensure healthy lives and promote well-being for all at all ages". In order to meet this target, there is a need to examine various factors that could hinder the achievement of the goal. Amongst the health issues raised by WHO is the infectious disease (e.g. HIV/AIDS). Health as WHO observed is said to be inherently significant as a human right but is also important to achieving pillars of sustainable development (economic development, environmental sustainability, social inclusion, and good governance). Sustainable development will be elusive in the absence of health and productive population. Another author reported that combating the spread of HIV/AIDS was critical to human progress as this disease disproportionately affect the development potential of dozens of countries ${ }^{12}$ HIV/AIDS has a complex linkage with poverty and in turn to the larger sustainable development ${ }^{13,14,15}$. Poverty can make people more vulnerable to HIV infection.

Meanwhile, at the end of 2016, an estimated 34.5 million adults globally were living with HIV/AIDS, where about 1 million died from AIDS $^{16}$. Moreover, some authors acknowledge HIV/AIDS as one of the most serious health crises in this century ${ }^{17,18}$. Some previous research on this epidemic has studied the economic and social determinants of HIV/AIDS transmission and methods for controlling its extension ${ }^{19,20}$. However, as recognition grew that HIV cases are more prominent amongst the person of working ages, economic researchers began to analyses the detrimental impact of HIV/AIDS on economic growth.

In 2016 for instance, about 25.73 million people were estimated to be living with HIV/AIDS in Africa16, among which 741, 000 died due to HIV/AIDS-related illness. Several studies has indicated that higher prevalence of HIV/AIDS within a country could lead to decrease in life expectancy, higher mortality rate, lower birth rates, lower human capital, and low job productivity $^{14,21-24}$. Similarly, various studies on theories and estimation methods has evolved to better understand the HIV/AIDS epidemics and how it affects real GDP 22,25 30 .

The literature on HIV/AIDS and economic growth in African countries have been prolific. The three established ground in the literature has been the mainstream of negative impact of HIV/AIDS on economic growth $^{15,24,26,28,29,31-35}$; the absence of relation between the two variables ${ }^{36,37}$ and finally, a minority and challenging ground that claims a positive impact of HIV on GDP growth ${ }^{38}$.

The previous studies explain, at least in part, the low impact of the epidemic, the impact of HIV/AIDS in long-term economic behavior were not yet clear. Virtually all the literature employed the traditional indicator for measuring countries progress (GDP), which according to an author, does not measure the country's wealth which could determine sustainable development ${ }^{4}$. A more disturbing explanation may be in the inappropriateness of the econometric models employed in determining the impact. This study assumed that models can be substantially improved by taking into account the sustainable development indicator and employed an appropriate panel data model estimator (Pooled Mean Group/ARDL) that has significant advantages over other estimators in analyzing panel data ${ }^{39}$.

Noticeably, the above literature leaves room for advancement in two critical areas, notably, the need to (i) go beyond GDP in monitoring a country's development progress by employing "Adjusted Net Savings" (ANS) as an indicator for sustainable development which has broader policy implications; (ii) employ a more robust econometrics model that accommodates most of shortcomings of the other econometrics model for panel data.

In view of the above, the macroeconomic analysis of the impact of HIV/AIDS on both short and long-run was determined by analyzing its impact on the sustainable development in Sub-Sahara Africa, while controlling for the role of health expenditure. The subsequent sections are structured as follows; Next section discusses the data and method, followed by the empirical analysis, while the last section includes the summary, conclusion, implications, and directions for future research.

\section{Methods}

The data employed in this study are adjusted net savings (ANS), which was measured as the gross national savings less the value of consumption of fixed capital; the variable has been established in previous studies as a good indicator for sustainable development ${ }^{40-44}$. Prevalence of HIV/AIDS, measured as the percentage of people aged between 15 and 49 who are infected with HIV; current health expenditure (HEX), measured as a percentage of GDP. It is the estimate of current health expenditures, includes health care goods and services consumed during each year. These variables are sourced 
from World development bank indicator ${ }^{45}$. The data are yearly and covers the period 1993 - 2016. The countries included in the panel are 23 sub-Saharan Africa countries (see appendix). The choice of countries in the panel was based on the availability of data for the variables included in the study during the observed period.

Our study is based on Pesaran et al., methodology, who introduced the pooled mean group (PMG) approach in the panel ARDL framework ${ }^{46}$. This estimator was settled for as a result of its advantages in comparison with other panel estimators. First, PMG/panel ARDL does not require a formal test for cointegration. Secondly, PMG minimizes the endogeneity problems and all the variables are considered to be endogenous. Thirdly, the testing for the order of variables integration is not generally required, i.e either the variable is $\mathrm{I}(0)$ or $\mathrm{I}(1)$ is not an issue inPMG. And lastly, the long-run and short-run variables are estimated simultaneously, lessening problems of omitted variables and autocorrelation.

In line with Pesaran et al., methodology, the panel ARDL model for this study including the long-run relationship between the variables is presented as follows:

$\Delta \mathrm{ANS}_{\mathrm{it}}={ }_{\mathrm{i}+\mathrm{i}} \mathrm{ANSi}_{\mathrm{t}-\mathrm{j}}+{ }_{\mathrm{il}} \mathrm{HPREV}_{\mathrm{i}, \mathrm{t}-\mathrm{l}}+{ }_{\mathrm{ir}} \mathrm{HEXi}, \mathrm{t}-\mathrm{r}+{ }_{1} \mathrm{ANSi}_{\mathrm{t}-1}+{ }_{2} \mathrm{HPREV}_{\mathrm{i}, \mathrm{t}-1}+{ }_{3} \mathrm{HEX}_{\mathrm{i}, \mathrm{t}-1}+{ }_{1 \mathrm{i}, \mathrm{t}}$ (eq. 1)

$\Delta \mathrm{HPREV}_{\mathrm{it}}={ }_{\mathrm{i}+\mathrm{ij}} \mathrm{HPREV}_{\mathrm{i}, \mathrm{t}-\mathrm{j}}+{ }_{\mathrm{il}} \mathrm{ANS}_{\mathrm{i}, \mathrm{t}-\mathrm{l}}+{ }_{\mathrm{irr}} \mathrm{HEX}_{\mathrm{i}, \mathrm{t}-\mathrm{r}}+{ }_{1} \mathrm{HPREV}_{\mathrm{i}, \mathrm{t}-1}+{ }_{2} \mathrm{ANS}_{\mathrm{i}, \mathrm{t}-1}+{ }_{3} \mathrm{HEX}_{\mathrm{i}, \mathrm{t}-\mathrm{1}}+{ }_{2 \mathrm{i}, \mathrm{t}}$ (eq. 2)

$\Delta \operatorname{HEX}_{\mathrm{it}}={ }_{\mathrm{i}+\mathrm{ij}} \mathrm{HEX}_{\mathrm{i}, \mathrm{t}-\mathrm{j}}+{ }_{\mathrm{il}} \mathrm{ANS}_{\mathrm{i}, \mathrm{t}-\mathrm{l}}+{ }_{\mathrm{ir}} \mathrm{HPREV}_{\mathrm{i}, \mathrm{t}-\mathrm{r}}+{ }_{1} \mathrm{HEXi}, \mathrm{t}-1+{ }_{2} \mathrm{ANS}_{\mathrm{i}, \mathrm{t}-1}+{ }_{3} \mathrm{HPREV}^{\mathrm{i}, \mathrm{t}-1}+{ }_{3 \mathrm{i}, \mathrm{t}}(\mathrm{eq} \cdot 3)$

Where ANS, HPREV and HEX are adjusted net saving (proxy for sustainable development), HIV/AIDS prevalence rate and health expenditure. $\Delta$ and $\sum \mathrm{k}_{\mathrm{it}}(\mathrm{k}=1$, $2,3)$ are the first difference operator and a white noise term. Also $\alpha 1$ denotes in (1), (2), and (3), a country specific intercept. The subscript I denotes a specific unit and is varying from 1 to $\mathrm{N}$. A reasonable generalization of cointegration test 43 from time series to panel data may formulate the null hypothesis of no cointegration between the three variables in Eq. (1) as follows: H0: 1
$=2=3=0$, while H1: at least one $\mathrm{k} 0(\mathrm{k}=1,2,3)$.

Similarly, the null hypothesis of no cointegration in equation (2) may be written as $\mathrm{H} 0: 1=2=3=0$. Also, in equation (3), the null hypothesis of no cointegration between the 3 variables may be formulated as $\mathrm{H}_{0}:{ }_{1}={ }_{2}$ $={ }_{3}=0$.

Subsequently, if the null hypothesis of cointegration is rejected, we estimate the long-run relationship for the first-panel ARDL described in Eq. (1) is presented as follows:

$\mathrm{ANS}_{\mathrm{it}}={ }_{\mathrm{i}+1 \mathrm{j}} \mathrm{ANS}_{\mathrm{i}, \mathrm{t}-\mathrm{j}}+{ }_{2 \mathrm{j}} \mathrm{HPREV}_{\mathrm{i}, \mathrm{t}-\mathrm{l}}+{ }_{3 \mathrm{j}} \operatorname{HEX}_{\mathrm{i}, \mathrm{t}-\mathrm{r}}+{ }_{\mathrm{v} 1 \mathrm{i}, \mathrm{t}}(\mathrm{eq} \cdot 4)$

In doing so, we have considered the assumption imposed by PMG approach, namely the coefficients of the long run relationship which are the same for each country in the panel. Meanwhile, this assumption has also been considered in the specification of the no cointegration null hypothesis associated with the three above-described ARDL models. Similarly, the longrun relationships corresponding to the two remaining ARDL models are established in the same way. The error correction terms are derived correspondingly from these relationships and they will be used accordingly.

The error correction models for the ARDL models described above are constructed as follows:

$\Delta \mathrm{ANS}_{\mathrm{it}}=\mathrm{i}+\mathrm{ANS}_{\mathrm{i}, \mathrm{t}-\mathrm{j}}+{ }_{\mathrm{il}} \mathrm{HPREV}_{\mathrm{i}, \mathrm{t}-\mathrm{l}}+{ }_{\mathrm{ir}} \mathrm{HEX}_{\mathrm{i}, \mathrm{t}-\mathrm{r}}+\alpha \mathrm{ECT}_{\mathrm{t}-1}+{ }_{1 \mathrm{i}, \mathrm{t}}($ eq. 5)

$\Delta \mathrm{HPREV}_{\mathrm{it}}={ }_{\mathrm{i}+\mathrm{ij}} \mathrm{HPREV}_{\mathrm{i}, \mathrm{t}-\mathrm{j}}+{ }_{\mathrm{il}} \mathrm{ANS}_{\mathrm{i}, \mathrm{t}-\mathrm{-}}+{ }_{\mathrm{ir}} \mathrm{HEX}_{\mathrm{i}, \mathrm{t}-\mathrm{r}}+\mathrm{bECT}_{\mathrm{t}-1}+{ }_{2 \mathrm{i}, \mathrm{t}}(\mathrm{eq} \cdot 6)$

$\Delta \operatorname{HEX}_{\mathrm{it}}={ }_{\mathrm{i}}+{ }_{\mathrm{ij}} \mathrm{HEX}_{\mathrm{i}, \mathrm{t}-\mathrm{j}}+{ }_{\mathrm{il}} \mathrm{ANS}_{\mathrm{i}, \mathrm{t}-\mathrm{l}}+{ }_{\mathrm{ir}} \mathrm{HPREV}_{\mathrm{i}, \mathrm{t}-\mathrm{r}}+\mathrm{cECT}_{\mathrm{t}-1}+{ }_{3 \mathrm{i}, \mathrm{t}}(\mathrm{eq} \cdot 7)$

Where the residual eki,t $(k=1,2,3)$ is independently and normally distributed with zero mean and constant variance, and ECTt-1 is the error correction term specified from the long-run equilibrium relationship. The parameters a,b,c shows the speed of adjustment to the equilibrium level.

African Health Sciences Vol 20 Issue 2, June, 2020
Having specified the models according to Pesaran et al., the next step is to give a descriptive statistics on the data, this will enable us to show and explain the characteristics of each variable in the model. Following steps will be correlation analysis, this is necessary to establish that the regressors do not have perfect or exact linear 
representations of one another. Subsequently, the unit root test will be conducted to ascertain that no variable is integrated of order two. This is to ensure that the model does not violate the assumption of PMG as highlighted by Pesaran et al., ${ }^{46}$. Furthermore, the esti- mation of the model will be done and inference from the analysis will be made to determine causality.

\section{Result and Discussion \\ Descriptive Statistics}

Table 1: Characteristics of the variables

\begin{tabular}{l|lll}
\multicolumn{1}{c}{} & ANS & HEX & HPREV \\
\hline Mean & 2.28 & 6.03 & 5.93 \\
Max. & 62.36 & 30.00 & 19.73 \\
Min. & -128.80 & 0.10 & 1.70 \\
Std. Dev. & 13.44 & 7.41 & 2.29 \\
Skewness & -2.67 & 1.66 & 1.23 \\
Kurtosis & 25.96 & 4.83 & 6.42
\end{tabular}

From table 1, it shows that the mean value for adjusted net saving (ANS) for the 23 countries in the panel during the period under study is 2.28 . This implies that the countries in our panel has $2.28 \%$ of their gross national income (GNI) committed to saving. The 6.03 mean values for health expenditure is an indication that average of $6.03 \%$ of the GDP of respective countries in our panel was spent on health, which could is considered to be low. Meanwhile, the 5.93 mean value for the HIV/AIDS prevalence depicts that $5.93 \%$ of the population ages between $15-45$ years in the countries in our panel are HIV carriers, and looking at the figure, it's alarming. The $19.73 \%$ maximum value for HIV/AIDS prevalence and $1.70 \%$ minimum value indicate that the SSA as a region is still being ravaged by the epidemic as observed from the data that none of the countries in the panel has less than $1.7 \% \mathrm{HIV} /$ AIDS prevalence. Another disturbing observation from the data is the

minimum value for health expenditure, which is as low as $0.01 \%$. The standard deviation values indicate that, while HPREV has a moderate degree of variation from the mean value, both ANS and HEX depicts a sharp variation from the mean value with 13.44 and 7.41 respectively.

Skewness and kurtosis values for the variables shows that ANS mirrors normal skewness and leptokurtic because the kurtosis value (25.96) is greater than 3. However, HPREV has a long-right tail (positive skewness) and leptokurtic (because $6.42>3$ ), and similarly, HEX has a long-right tail (positive skewness) and leptokurtic as well (because $4.83>3$ ).

The description above of the variables tell us that in our data, we have more high values above the average sample size.

\section{Correlation analysis}

Table 2. Correlation analysis result

\begin{tabular}{l|lll} 
& ANS & HPREV & HEX \\
\hline ANS & 1.00 & & \\
HPREV & 0.29 & 1.00 & \\
HEX & 0.09 & 0.23 & 1.00
\end{tabular}

From table 2, we can deduce that the regressors are not linearly dependent on each other which indicate that there is no multicollinearity problem with the model. Unit root test

Though Pesaran et al., commented that the variables for Pooled Mean Group (PMG) estimator could either be integrated on $\mathrm{I}(0)$ or $\mathrm{I}(1)$ in order for the variable not to lose its predictive power ${ }^{46}$. However, an author opined that panel ARDL does not generally require knowledge of the order of integration of variables ${ }^{47}$. Nevertheless, we apply Levin, Lin \& Chu; Breitung t-stat; Im Pesaran and Shin W-stat; ADF Choi Z; PP Choi-Z; and Hadri test for both levels and their first difference with an intercept and trend. This was done to ascertain the 
stationarity properties of the variable to enhance the Table ( 3 \& 4) indicate that ANS, HPREV, and HEX robustness of our results. The results as presented in are stationary variables, therefore we could use panel ARDL model (PMG).

Table 3. Panel unit root result (at level)

\begin{tabular}{l|llllll}
\multicolumn{2}{l}{ ANS } & \multicolumn{3}{l}{ HPREV } & \multicolumn{2}{l}{ HEX } \\
\hline & Intercept & Trend & Intercept & Trend & Intercept & Trend \\
LLC & $-5.73(0.00)$ & $3.54(0.00)$ & $-4.73(0.00)$ & $-2.02(0.02)$ & $-11.88(0.00)$ & $-11.45(0.00)$ \\
IPS & $-6.19(0.00)$ & $-4.74(0.00)$ & $-6.43(0.00)$ & $-3.06(0.00)$ & $-9.35(0.00)$ & $-9.50(0.00)$ \\
BREITUNG & ---------- & $-1.43(0.08)$ & ------------ & $-1.50(0.07)$ & ------------ & $-0.02(0.49)$ \\
HADRI & $4.21(0.00)$ & $4.13(0.00)$ & $2.81(0.00)$ & $6.89(0.00)$ & $9.99(0.00)$ & $11.11(0.00)$ \\
ADF CHOI- & $-6.05(0.00)$ & $-4.40(0.00)$ & $-6.09(0.00)$ & $-2.77(0.00)$ & $-7.52(0.00)$ & $-7.11(0.00)$ \\
Z & & & & & & $-2.17(0.02)$ \\
PP CHOI-Z & $-7.72(0.00)$ & $-6.53(0.00)$ & $-5.19(0.00)$ & $-2.54(0.01)$ & $-3.98(0.00)$ & -
\end{tabular}

Note: the values in parentheses are the corresponding $p$-value

Table 4. Panel unit root result (at first difference)

\begin{tabular}{l|llllll}
\multicolumn{2}{l}{ ANS } & \multicolumn{5}{c}{ HPREV } \\
\hline & Intercept & Trend & Intercept & Trend & Intercept & Trend \\
LLC & $-21.93(0.00)$ & $-18.33(0.00)$ & $-13.22(0.00)$ & $-8.45(0.00)$ & -11.57 & $-8.21(0.00)$ \\
& & & & & $(0.00)$ & \\
IPS & $-22.13(0.00)$ & $-19.76(0.00)$ & $-16.83(0.00)$ & $-13.11(0.00)$ & $-8.47(0.00)$ & $-6.58(0.00)$ \\
BREITUNG & ------------ & $-8.22(0.00)$ & ---------- & $-1.65(0.05)$ & ------------ & $-2.52(0.01)$ \\
HADRI & $3.24(0.00)$ & $17.42(0.00)$ & $-0.71(0.76)$ & $8.94(0.00)$ & $9.73(0.00)$ & $11.63(0.00)$ \\
ADF CHOI- & $-17.43(0.00)$ & $-15.16(0.00)$ & $-14.23(0.00)$ & $-10.99(0.00)$ & $-7.23(0.00)$ & $-5.06(0.00)$ \\
Z & & & & & & \\
PP CHOI-Z & $-21.80(0.00)$ & $-24.35(0.00)$ & $-17.81(0.00)$ & $-16.50(0.00)$ & $-6.00(0.00)$ & $-4.95(0.00)$
\end{tabular}

Note: the values in parentheses are the corresponding $p-$ value

Cointegration analysis

Table 5. Pedroni Cointegration test statistics

\begin{tabular}{l|l} 
Test & Statistics \\
\hline Panel v-statistics & -0.60 \\
Panel rho statistics & $-2.24 * * *$ \\
Panel PP-Statistics & $-6.17 * * *$ \\
Panel ADF-Statistics & $-6.97 * * *$ \\
Group rho-Statistics & $-2.31 * * *$ \\
Group PP-Statistics & $-7.11^{* * *}$ \\
Group ADF-Statistics & $-7.44 * * *$ \\
& \\
Note: *** indicate 1\% significance level &
\end{tabular}

The result from Table 5 depicts that only Panel v statistics out of seven statistics failed to reject the no cointegration null hypothesis, while the remaining six statistics reject the no cointegration null hypothesis at $1 \%$ significance level. In view of the result, we can submit that there is a long-run relationship between ANS, HPREV and HEX. 
PMG long-run estimates

Table 6. Long-run estimates

\begin{tabular}{l|lll}
\multicolumn{4}{c}{ Independent Variables } \\
\hline Dependent variables & ANS & HPREV & HEX \\
ANS & - & $-2.21^{* * *}(0.43)$ & $-0.020(0.19)$ \\
HPREV & $-0.067^{* * *}(0.01)$ & - & $0.09 * *(0.04)$ \\
HEX & $0.058^{* * *}(0.013)$ & $0.14^{* *}(0.07)$ & - \\
Note: The values in parentheses are standard error & & \\
$* * *$ Indicate $1 \%$ level of significance & & \\
$* *$ indicate $5 \%$ level of significance &
\end{tabular}

In this section, the long-run causal relationships findings between ANS, HPREV, and HEX were discussed, and the results as presented in Table 6 shows that when ANS is the dependent variable (eq. 1), HPREV has a negative long-run effect on the ANS at $1 \%$ significance level. This result implies that at the long-run, the prevalence of HIV/AIDS will have negative influence on sustainable development of the SSA countries. Moreover, when HPREV is the dependent variable (eq. 2), ANS has a negative long-run effect on the HPREV, while the influence of HEX is found to be positive at the longrun. This is an indication that both ANS and HPREV determine each other at the long. In other words, there is a bi-directional relational causal relationship between sustainable development and HIV/AIDS prevalence in SSA which is statistically significant. Meanwhile, the positive influence of HEX on the prevalence of HIV in the long-run implies that, if the rate of expenditure committed by the SSA countries to health continues, it will increase the prevalence of the epidemic instead of reducing it. In other words, the percentage of GDP spending on health needs to be increased. In addition, the influence of HPREV and ANS were determined on the HEX (eq. 3), the results shows that both ANS and HPREV has a positive long-run effect on HEX and also statistically significant at $1 \%$ and $5 \%$ respectively. The result is an indication that the higher the epidemic prevalence, the higher the fund that will be committed to health expenditure, so also an increase in the ANS, will translate to more funds for the health. In summary, long-run bidirectional was found to exist between ANS and HPREV, and HPREV and HEX, while unidirectional long-run causal relationship was found between ANS and HEX. 
Table 7. PMG short-run estimate, $\triangle \mathrm{ANS}$ is the dependent variable

\begin{tabular}{l|ll} 
Variables & Coefficients & Standard Error \\
\hline ECT & $-0.56^{* * *}$ & 0.08 \\
$\Delta($ ANS $(-1))$ & -0.031 & 0.054 \\
$\Delta($ HEX $)$ & 3.61 & 4.50 \\
$\Delta($ HEX $(-1))$ & $-11.92^{*}$ & 6.62 \\
$\Delta($ HPREV $)$ & -1.10 & 0.77 \\
$\Delta($ HPREV $(-1))$ & 0.86 & 0.83 \\
Constant & $7.84 * * *$ & 1.87
\end{tabular}

Note: *** and $*$ indicate $1 \%$ and $10 \%$ significance level respectively.

Table 8. PMG short-run estimate, $\triangle \mathrm{HEX}$ is the dependent variable

\begin{tabular}{l|ll} 
Variables & Coefficient & Standard Error \\
\hline ECT & $-0.03^{*}$ & 0.01 \\
$\Delta($ HEX $(-1))$ & $0.50^{* * *}$ & 0.08 \\
$\Delta($ ANS $)$ & -0.0008 & 0.002 \\
$\Delta($ ANS $(-1))$ & -0.00042 & 0.0011 \\
$\Delta($ HPREV $)$ & 0.009 & 0.006 \\
$\Delta($ HPREV $(-1))$ & -0.002 & 0.007 \\
Constant & $0.35^{* * *}$ & 0.13
\end{tabular}

Note: $* * *$ and $*$ indicate $1 \%$ and $10 \%$ significance level respectively.

Table 9. PMG short-run estimate, $\triangle \mathrm{HPREV}$ is the dependent variable

\begin{tabular}{l|ll} 
Variable & Coefficient & Standard Error \\
\hline ECT & $-0.60^{* * *}$ & 0.10 \\
$\Delta($ HPREV(-1) & $0.18^{* * *}$ & 0.07 \\
$\Delta($ ANS $)$ & $0.022^{* * *}$ & 0.009 \\
$\Delta($ ANS $(-1))$ & $0.016^{* * *}$ & 0.006 \\
$\Delta($ ANS $(-2))$ & 0.001 & 0.012 \\
$\Delta(\operatorname{HEX})$ & $0.87^{* *}$ & 0.37 \\
$\Delta($ HEX $(-1))$ & -0.29 & 0.65 \\
$\Delta($ HEX $(-2))$ & -1.34 & 0.96 \\
Constant & $3.46^{* * *}$ & 0.54
\end{tabular}

Note: $* * *, * *$ and $*$ indicate $1 \%$ and $5 \%$ significance level respectively.

As presented in table $(7,8 \& 9)$, it shows the shortrun coefficients and the cointegration vectors for ANS, HEX, and HPREV respectively. Suffice to say that, the signs and intervals of ECTs from the 3 tables are consistent with theory, which according to an author stated that a negative ECT ranges between 0 and 1, is imperative for a stable error correction mechanism ${ }^{41}$. While a positive ECT implies a deviation from the equilibrium, a negative ECT is important for the restoration of equilibrium following an exogenous shock. 
The ECT coefficient from the tables shows that model of $\triangle$ ANS, $\triangle$ HEX and $\triangle$ HPREV relationship can be restored to its long-run equilibrium. The analysis of equation (5) as presented in table (7) indicate that there is long-run cointegration among the variables at $1 \%$ significance level, and the ECT coefficient of (-0.56) implies that any deviation from the long-run equilibrium is corrected at $56 \%$ adjustment speed. In addition, the significance of ECT, it is an indication that a stable long-run relationship exists between sustainable development (ANS) and the independent variable is significant.

From table 8, equation (7), the result shows a stable long-run relationship between HPREV and other variables at 10\% significance level, while the model could be significantly restored to its long-run equilibrium at 3\% adjustment speed in the presence of a shock. The result shows further that there is short-run causality running from health expenditure (HEX) to sustainable development (ANS).

Analysis for equation (6) as presented in table 9 reveals that there is a stable long-run relationship between HEX and other variables which is statistically significant at $1 \%$ level, and in the presence of a shock, the model could be significantly restored to its long-run equilibrium at $60 \%$ adjustment speed. As it could be observed from the table (9), it shows that there is shortrun causality running from sustainable development (ANS) to HIV/AIDS prevalence (HPREV) and also from health expenditure (HEX) to HIV/AIDS prevalence (HPREV).

\section{Causality test}

Long-run causality can be inferred from table 6 , it could be deduced from the table that HPREV has long-run causality on ANS at 1\% significance level. Also, ANS and HEX have a long-run causality on HPREV and are statistically significant at $1 \%$ and $5 \%$ level respectively. Similarly, ANS and HPREV has a long-run causality on HEX at $1 \%$ and $5 \%$ significance level respectively. The result of health expenditure (HEX) not having a longrun causality on sustainable development is understandable, owing to the fact that, health issue in most cases manifest within a short-term. Moreover, an inference could be made from the table $(7,8 \& 9)$ that all the variables together ( $\triangle$ HPREV and $\triangle \mathrm{HEX}$ ) jointly have an impact on ANS at the long-run at 1\% significance level. Similarly, $\triangle \mathrm{ANS}$ and $\triangle \mathrm{HPREV}$ jointly have a long-run effect on $\triangle \mathrm{HEX}$ at $10 \%$ significance level, while $\triangle \mathrm{ANS}$ and $\triangle$ HEX together have a significant long-run effect on $\triangle$ HPREV at $1 \%$ significant level.
As observed from table 6 , there is an established bi-directional causality from HIV/AIDS prevalence (HPREV) to sustainable development (ANS); and HIV/AIDS prevalence (HPREV) to health expenditure (HEX), while a uni-directional causality is observed from health expenditure (HEX) to sustainable development (ANS).

\section{Discussion}

Sustainable development is a complex concept of the world and currently the main challenge for all continents and countries, most especially the developing regions. Most authors have argued the significance of a healthy society in achieving sustainable development goals. The impact of HIV/AIDS on economic growth has been investigated by a number of past studies ${ }^{22,24,26,28,29,36}$, whereas, others have explored the interaction between a number of factors together with HIV/AIDS and economic growth ${ }^{22,23}$.

However, despite theoretical suggestion that the development of any countries or region could not be adequately accounted for using traditional economic growth indicator - GDP ${ }^{4,7}$, studies on sustainable development and HIV/AIDS is still rare, but an attempt has been made and work is still ongoing on having a generally accepted indicator for sustainable development ${ }^{4,5,8,9}$. This study thus investigates the relationship between sustainable development and HIV/AIDS, whether there is a short or long-run relationship and the significance of the relationship, also determining the direction of the causal relationship. This is imperative to serve as policy guidance on HIV/AIDS and sustainable development in sub-Saharan Africa, where HIV/AIDS prevalence rate is comparatively high and thus serve as a significant challenge for achieving sustainable development goals by 2030 .

An adapted version of Pesaran et al., ${ }^{46}$, Pooled Mean Group (PMG) or Panel ARDL was used in this study to evaluate the impact of HIV/AIDS prevalence on sustainable development in Sub-Saharan Africa. The main objective of the study is to evaluate the long-run relationship between HIV/AIDS prevalence and sustainable development, and also to determine the direction of causality between the variables. Our study is a novel study on the empirical modeling of sustainable development and HIV/AIDS prevalence relationship. Previous studies are tilted towards the HIV - economic growth relationship. Meanwhile, a similar recent study was conducted by Odugbesan \& Rjoub ${ }^{48}$ which examined the relationship between sustainable development and HIV/AIDS prevalence with the inclusion of human capital and good governance. 
This study established a long-run causality from HIV/ AIDS to sustainable development (ANS). Our finding is in consistent with the study of Odugbesan \& Rjoub ${ }^{48}$ who established similar result for SSA countries. In addition, our finding is in agreement with some previous studies $^{13,14,15}$ that submitted in their studies that HIV/ AIDS has a significant linkage with poverty and subsequently the sustainable development. This is an indication that to achieve a sustainable development goal on healthy society in sub-Saharan Africa by 2030, more efforts are required to tame the scourge of HIV/AIDS as the study suggests.

Sustainable development and health expenditure were also established in the study to have a long-run causality on HIV/AIDS prevalence, so also, sustainable development and HIV/AIDS were confirmed to have long-run causality on health expenditure. Another findings from the study is that, HIV/AIDS (HPREV) and health expenditure (HEX) jointly have an impact on sustainable development (ANS), also sustainable development (ANS) and HIV/AIDS (HPREV) significantly influenced health expenditure (HEX), while sustainable development (ANS) and health expenditure (HEX) were also found to have a joint impact on HIV/AIDS. The direction of causality as inferred from the analysis reveals that there is bi-directional causality between sustainable development and HIV/AIDS, this result contrast the study of Odugbesan \& Rjoub ${ }^{48}$ that did similar study but found a unidirectional causal relationship between sustainable development and HIV/AIDS prevalence. Moreover, bidirectional causal relationship was found between HIV/AIDS prevalence and health expenditure. However, uni-directional causality was established running from health expenditure (HEX) to sustainable development (ANS).

\section{Conclusion}

The policy implications from this study could be examined notably on the long-run relationship established; that is, the ability to restore the long-run relationship in the event of disequilibrium. The established longrun relationship implies that a carefully tailored policy on HIV/AIDS and health expenditure is required in the post-2019 development agenda. But it should be framed in such a way that the sustainable development is not compromised by HIV/AIDS and health expenditure; the responsiveness of HIV/AIDS to sustainable development is maintained at a minimum which would require more efforts on HIV/AIDS control programs and increase in health expenditure. Moreover, the evidence that in the presence of an exogenous shock, sustainable development, HIV/AIDS and health expenditure can be significantly adjusted to restore the long-term relationship means that the fundamentals of error correction terms corresponding to each of the variables need to be consolidated.

Differently, from employing a robust panel data model estimator (PMG), the result of this study make new contributions to the econometrics, sustainable development, and health studies literature in several ways. Using PMG by Pesaran et al., ${ }^{46}$ in estimating the model, this study contributes to the literature on the Panel ARDL model that the order of integration is of no importance in PMG estimator.

Secondly, this study contributes to the theoretical suggestions of moving beyond GDP as a measure of a country's progress. In the sense that, sustainable development was employed in this study to measure the region's development progress, and not only that the result is different from previous studies, it as well shows more robustness in terms of methodology.

Thirdly, although the result of a good number of previous research that directly investigated the economic growth and HIV/AIDS relationship have been mixed, efforts at explaining how and why this might be the case are limited. Therefore, this study makes a new and distinctive contribution to the international literature by revealing that HIV/AIDS prevalence has a significant impact on sustainable development, whether there will be a reduction or increase when other factors are added will be our focus for future research.

Lastly, this study empirically offers new significant insight on, and expansion of, the efforts at explaining the conflicting results of previous research that has investigated the nexus between economic development and HIV/AIDS prevalence.

This study includes one dependent variable and one control variable, though the study established significant results, however, there is a need for future research to include other independent variables in the model. This becomes necessary because formulating policy in regards to health issues requires a thorough and statistically established research in formulating such policies.

\section{Key points for decision makers}

-The study established that HIV/AIDS prevalence in SSA will impact on the sustainable development at the long-run.

-The study reveals a joint causality of HIV/AIDS prevalence and health expenditure in SSA on sustainable development at the long-run. 
-The implication of this study is that efforts on the HIV/AIDS control programs should be enhanced for the SSA countries to be able to attain sustainable development goals target.

\section{Conflict of interest}

The authors declare no conflict of interest. There was no funding sponsor for the design of the study; the collection, analysis or interpretation of data; the writing of the manuscript, therefore, no conflict of interest in the decision to publish the results.

\section{References}

1. UNDP, 2016. Human Development Reports. http:// hdr.undp.org/en/2016-report. (Accessed 20 February 2018).

2. Dasgupta, P., Duraiappah, A., Managi, S., Barbier, E., Collins, R., Fraumeni, B.,

Gundimeda, H., Liu, G., Mumford, K., 2015. How to measure sustainable progress. Science 350, 748e 748.

3. Polasky, S., Bryant, B., Hawthorne, P., Johnson, J., Keeler, B., Pennington, D., 2015.

Inclusive wealth as a metric of sustainable development. Annu. Rev. Environ. Resour. 40, 445e466.

4. Lange, G. M., Wodon, Q., \& Carey, K. (Eds.). (2018). The changing wealth of nations 2018: Building a sustainable future. The World Bank.

5. World Bank (2011). The Changing Wealth of $\mathrm{Na}$ tions: Measuring Sustainable Development in the New Millennium. The World Bank, Washington DC. www.worldbank.org

6. Boţa-Avram, C., Groşanu, A., Răchişan, P. R., \& Gavriletea, M. D. (2018). The Bidirectional Causality between Country-Level Governance, Economic Growth and Sustainable Development: A Cross-Country Data Analysis. Sustainability, 10(2), 502.

7. Mignaqui, V. (2014). Sustainable development as a goal: social, environmental and economic dimensions. International Journal of Social Quality, 4(1), 57-77.

8. Neumayer, E. 2012. "Human Development and Sustainability." Journal of Human Development and Capabilities: A Multi-Disciplinary Journal for People-Centered Development 13(4)

9. Crabtree, A. 2012. "A Legitimate Freedom Approach to Sustainability: Sen, Scanlon and the Inadequacy of the Human Development Index." International Journal of Social Quality 2(1): 24-40.

10. UNEP (United Nations Environment Programme). 2012. Global Environment Outlook: Environment for the Future We Want - GE05. Nairobi: UNEP

11. WHO 2016. Health in the Sustainable Develop- ment Goals. http://www.searo.who.int/entity/health_ situation_trends/health_in_sustainable_devlop_g oals.pdf

12. Sustainable Development Solutions Network (SDSN 2014). Health in the framework of Sustainable Development. http://unsdsn.org/wp-content/uploads/2014/02/Health- For- All-Report.pdf

13. Ntim, C. G. (2016). Corporate governance, corporate health accounting, and firm value: The case of HIV/AIDS disclosures in Sub-Saharan Africa. The International Journal of Accounting, 51(2), 155-216.

14. UNAIDS 2018. The sustainable development goals and the HIV response. ww.unaids.org/sites/default/ files/media_asset/SDGsandHIV_en.pdf

15. Salinas, Gonzalo, \& Markus H. (2006), HIV/AIDS: The Impact of Poverty and Inequality. International Monetary Fund, WP/06/126.

16. UNAIDS (2017). UNAIDS Data 2017. www.unaids.org

17. Soobaroyen, T., \& Ntim, C. G. (2013). Social and environmental accounting as symbolic and substantive means of legitimation: The case of HIV/AIDS reporting in South Africa. Accounting Forum, 37(2), 92-109. 18. UNAIDS (2014). Report on global AIDS epidemic. (Available at) http://www.unaids.org/globalreport. htm (Accessed: 5 March 2018)

19. Djukpen, R. O. (2012). Mapping the HIV/AIDS epidemic in Nigeria using exploratory spatial data analysis. Geo Journal, 77(4), 555-569.

20. Erinosho O., Dike N., Joseph R., Isiugo-Abanihe U., Aderinto A.A.(2013). Methodological Issues in HIV-Related Social Research in Nigeria, African Journal of Reproductive Health / La Revue Africaine de la SantéReproductive, 17(4), pp.146-155. http://www.jstor.org/stable/24362096.

21. Rahaman, A., Neu, D., \& Everett, J. (2010). Accounting for social-purpose alliance: Confronting the HIV/AIDS pandemic in Africa. Contemporary Accounting Research, 27(4), 1093-1129.

22. Fortson J.G. (2011). Mortality Risk and Human Capital Investment: The Impact of HIV/AIDS in sub-Saharan Africa. The Review of Economics and Statistics, vol.93, No.1, pp.1-15. http://www.jstor.org/stable/23015916. 23. Chicoine, L. (2012). AIDS mortality and its effect on the labor market: Evidence from South Africa. Journal of Development Economics, 98(2), 256-269.

24. Asiedu, E., Jin, Y., \& Kanyama, I. K. (2015). The impact of HIV/AIDS on foreign direct investment: Evidence from Sub-Saharan Africa. Journal of African Trade, 2(1-2), 1-17.

25. Rampersad, R. (2010). An assessment of corpo- 
rate governance and HIV/AIDS in the South African corporate sector. African Journal of Business Management, 4(11), 2269-2276.

26. Roy S. (2014). The effects of HIV/AIDS on economic growths and human capitals: a panel study evidence from Asian countries. AIDS Care, 26:12, pp.1568-1575, DOI:10.1080/09540121.2014.923812. http://www.tandfonline.com/loi/cods20

27. Couderc, N., \& Ventelou, B. (2005). AIDS, economic growth and the epidemic trap in Africa. Oxford Development Studies, 33(3-4), 417-426.

28. Igwike, R. S., \& Hussain, M. E. (2012). Examining the impact of HIV-Prevalence on economic growth in Sub-Saharan Africa: a panel data analysis.

29. Maijama D., Samsudin S. and Mohd Khan S. (2015). HIV/AIDS and Economic Growth: Emprical Evidence from Sub-Saharan Africa. Research in Applied Economics, vol.7, No.4. DOI: 10.5296/rae.v7i4.8426. http://www.researchgate.net/publication/307856394

30. Essig, A., Kang, S., \& Sellers, R. (2015). The Relationship between HIV Infection Rates and GDP Per Capita in African Countries.

31. Bonnel, R. (2000), HIV/AIDS and Economic Growth: A Global Perspective.South African Journal of Economics, Volume 68, Issue 5, pages 360-379.

32. Arndt, Channing \& Jeffery D. L. (2000), The Macro Implications of HIV/AIDS in South Africa: A Preliminary Assessment. AFTM1, the World Bank, August, 2000 .

33. Arndt, C. (2003), HIV/AIDS, Human Capital, and Economic Growth Prospects of Mozambique. Working Paper.

34. Corrigan, Paul, Gerhard \& Fabio M. (2005), AIDS Crisis and growth. Journal of Development Economics, Volume 77, Issue 1, June 2005, Pages 107-124.

35. Cuesta J. (2010). How much of a threat to economic growth is a mature AIDS epidemic? Applied Economics, 4224, pp.3077-3089. DOI:10.1080/00036840801964849. http://www.tandfonline.com/loi/cods20

36 Bloom, D. and Mahal, A. (1997). Does the AIDS Epidemic Threaten Economic Growth? Journal of Econometrics, 77(1):105-124.

37. Dixon, McDonald, \& Jennifer R. (2001), AIDS and
Development in Africa. Journal of International Development, Special Issue, Volume 13, Issue 4, pages 381-389, May.

38. Young, A. (2005). The gift of the dying: the tragedy of AIDS and the welfare of future African generations, Quarterly Journal of Economics, 120, 423-66

39. Asongu, S., El Montasser, G., \& Toumi, H. (2016). Testing the relationships between energy consumption, CO 2 emissions, and economic growth in 24 African countries: a panel ARDL approach. Environmental Science and Pollution Research, 23(7), 6563-

40. Nourry, M. Measuring sustainable development: Some empirical evidence for France from eight alternative indicators. Ecol. Econ. 2008, 67, 441-456.

41. Gnègnè, Y. Adjusted net saving and welfare change. Ecol. Econ. 2009, 68, 1127-1139.

42. Thiry, G.; Cassiers, I. Alternative indicators to GDP: Values behind numbers. Adjusted net savings in question. Appl. Res. Qual. Life 2010, 23, 1-23.

43. Lange, G.M.; Wodon, Q.; Carey, K. (Eds.) The Changing Wealth of Nations 2018: Building a Sustainable Future; The World Bank: Washington, DC, USA, 2018.

44. Odugbesan, J. A., \& Rjoub, H. (2019). Relationship among HIV/AIDS Prevalence, Human Capital, Good Governance, and Sustainable Development: Empirical Evidence from Sub-Saharan Africa. Sustainability, 11(5), 1348.

45. World Bank (2018). World Band Development Indicators. http://databank.worldbank.org/data/home. aspx

46. Pesaran, M.H., Y. Shin, and R.J. Smith (1999). "Pooled mean group estimation of dynamic heterogeneous panels". Journal of American Statistical Association 94(446), pp. 621-634.

47. Kumar, S., Webber, D. J., \& Fargher, S. (2012). Wagner's Law revisited: cointegration and causality tests for New Zealand. Applied Economics, 44(5), 607-616.

48. Odugbesan, J. A., \& Rjoub, H. (2019). Relationship among HIV/AIDS Prevalence, Human Capital, Good Governance, and Sustainable Development: Empirical Evidence from Sub-Saharan Africa. Sustainability, 11(5), 1348. 